UCID-21621

\title{
An Alternative Strategy for Low Specific Power Reactors to Power Interplanetary Spacecraft, Based on Exploiting Lasers and Lunar Resources
}

B.G. Logan

February 2, 1989

This is an informal report intended primarily for internal or limited external distribution. The opinions and conclusions stated are those of the author and may or may not be those of the Laboratory.

Work performed under the auspices of the U.S. Department of Energy by the Lawrence Livermore National Laboratory under Contract W-7405-Eng-48. 


\section{DISCLAIMER}

This report was prepared as an account of work sponsored by an agency of the United States Government. Neither the United States Government nor any agency Thereof, nor any of their employees, makes any warranty, express or implied, or assumes any legal liability or responsibility for the accuracy, completeness, or usefulness of any information, apparatus, product, or process disclosed, or represents that its use would not infringe privately owned rights. Reference herein to any specific commercial product, process, or service by trade name, trademark, manufacturer, or otherwise does not necessarily constitute or imply its endorsement, recommendation, or favoring by the United States Government or any agency thereof. The views and opinions of authors expressed herein do not necessarily state or reflect those of the United States Government or any agency thereof. 


\section{DISCLAIMER}

Portions of this document may be illegible in electronic image products. Images are produced from the best available original document. 


\section{DISCLAIMER}

This document was prepared as an account of work sponsored by an agency of the United States Government. Neither the United States Covernment nor the University of California nor any of their employees, makes any warranty, express or implied, or assumes any legal liability or responsibility for the accuracy, completeness, or usefulness of any information, apparatus, product, or process disclosed, or represents that its use would not infringe privately owned rights. Reference herein to any specific commercial products, process, or service by trade name, trademark, manufacturex, or otherwise, does not necessarily constitute or imply its endorsement, recommendation, or favoring by the United States Government or the University of California. The views and opinions of authors expressed herein do not necescarily state or reflect those of the United States Government or the University of California, and shall not be used for advertising or product endorsement purposes.

\author{
Printed in the United States of America \\ Available from \\ National Technical Information Service \\ U.S. Department of Commence \\ 5285 Port Royal Road \\ Springfield, VA 22161
}

Price

Code

A01
Page

Range

Microfiche

Papercopy Prices

$\begin{array}{ll}\mathbf{A 0 2} & \mathbf{0 0 1}-\mathbf{0 5 0} \\ \mathbf{A 0 3} & 051-100 \\ \mathbf{A 0 4} & \mathbf{1 0 1 - 2 0 0} \\ \mathbf{A 0 5} & 201-\mathbf{3 0 0} \\ \mathbf{A 0 6} & \mathbf{3 0 1 - 4 0 0} \\ \text { A07 } & 401-500 \\ \text { A08 } & \mathbf{5 0 1 - 6 0 0} \\ \text { A09 } & 601\end{array}$

$01-050$

$101-200$

$301-400$

601 
An Alternative Strategy for Low Specific Power Reactors to Power Interplanetary Spacecraft, Based on Exploiting Lasers and Lunar Resources

\author{
B. G. Logan \\ UCID--21621 \\ Lawrence Livermore National Laboratory \\ DE89 007688
}

\title{
INTRODUCTION
}

A key requirement setting the minimum electric propulsion performance (specific power $\alpha_{e}=\mathrm{kW}_{e} / \mathrm{kg}$ ) for manned missions to Mars is the maximum allowable radiation dose to the crew during the long transits between Earth and Mars. Penetrating galactic cosmic rays and secondary neutron showers give about $0.1-\mathrm{rem} /$ day dose, which only massive shielding (e.g., a meter of concrete) can reduce significantly. With a humane allowance for cabin space, the shielding mass becomes so large that it prohibitively escalates the propellant consumption required for reasonable trip times.

One solution may be to use permanently cycling spaceships with transfer vehicles, which avoid acceleration and deceleration of large shielding mass, but which constrain roundtrip periods to long 4-year cycles. A more desirable alternative is to develop sufficient propulsion system performance for sufficiently short trip times that maximum dose limits not be exceeded. Such dose limits are not yet promulgated for space travel, but for reference, the US limits routine doses to nuclear plant workers to $5 \mathrm{rem} /$ year and $25 \mathrm{rem}$ for one-time accident exposures. At $25 \mathrm{rem} /$ exposure for astronauts, the roundtrip time must be less than 250 days $(0.7$ year), at a dose rate of $0.1 \mathrm{rem} /$ day. Then, for the Mars mission requirements, the minimum specific power for less than 1000-ton initial mass and 0.7 -year roundtrip travel time is $0.33 \mathrm{~kW} / \mathrm{kg}$ (Fig. 1). Corresponding total mission delta V, specific impulse/power, and propellant consumption are indicated in Figs. 2, 3, and 4, respectively. Dose limits lower than 25 rem would require higher specific power capability than $0.33 \mathrm{~kW} / \mathrm{kg}$.

Given the present state of knowledge about solar, fission, and fusion candidates for spacecraft power, we cannot say that such minimum specific power values can be assured with any candidate, although, with various degrees 
of optimism, we might say that such a performance level might be reached with advances in technology. Rather than have the fate of important Mars and other manned interplanetary missions depend solely on achieving such threshold specific powers, it would be prudent to seek other paths to achieve such missions, even if fission or fusion reactor developments turn out with lower specific power than $0.33 \mathrm{~kW} / \mathrm{kg}$. One such concept, which I dub LASERPATH, would site lower specific power reactors at a lunar base, and use their electricity to power large free electron lasers (FELs), which in turn remotely power lower mass spacecraft at much higher specific powers. If reactors at $0.33 \mathrm{~kW}_{\mathrm{e}} / \mathrm{kg}$ were indeed available, it could still be more advantageous to base them on the moon for laser-powering the vehicles instead of directly powering them on-board with the same reactor specific power, provided that (a) the laser conversion efficiency were sufficiently high at sufficiently short wavelengths, (b) the specific power of laser-driven photovoltaics (for the vehicle electrical power) were sufficiently greater than $0.33 \mathrm{~kW} / \mathrm{kg}$, and (c) a large fraction of the lunar-based reactors and lasers could be constructed from indigenous lunar materials. The following description of the LASERPATH concept and comparisons of LASERPATH-powered cases with on-board reactor-powered cases are not an attempt to fully substantiate these assumptions, but rather illustrate possibilities that warrant further study.

\section{LUNAR-BASED FREE ELECTRON LASERS}

There have been several previous assessments of laser space power transmission. 1,2 However, since these studies were completed, the recent advent of FELs in the US Strategic Defense Initiative (SDI) program and in the Japanese Center for Science and Technology Development at Osaka appear much more promising to meet the desired characteristics for lunar-based laser power transmission: 100-MW-level high average power, high conversion efficiency (20 to $40 \%)$, high specific power $(21 \mathrm{~kW} / \mathrm{kg})$, and tunability to any desired wavelength. The last characteristic is important to match photon quantum energy $h \nu$ to the optimum quantum energy above the bandgap of the vehicle photovoltaic receiver, to achieve high photovoltaic power density and conversion efficiency (described in the next section). 
Figure 5 illustrates the basic components of one type of $\mathrm{FEL}$, called Induction-Linac FEL, or IFEL, which is under development at the Lawrence Livermore National Laboratory (LLNL). LLNL recently demonstrated $40 \%$ conversion efficiency at peak powers of $1 \mathrm{GW}$ in a microwave IFEL, and experiments at much shorter wavelengths are under way. Another basic type of FEL driven by an RF Linac is under development at Los Alamos National Laboratory (and also in Japan). Both approaches accelerate an electron beam to high energies and pass the beam through a series of alternating transverse magnetic fields, called a wiggler, as shown in Fig. 5. Provided a certain relationship between the electron energy, input light wavelength, wiggler field, and wiggler wavelength are satisfied, the periodic transverse motion of the electron beam in the wiggler field amplifies the input light intensity. Because the gain medium in the FEL is simply a bunch of free electrons traveling in a vacuum magnetic field, and because there need be no window in space vacuum between the wiggler and reflective (Cassegrain-type) transmitter optics, there is no fundamental limit on the laser intensity set by the breakdown of materials, nor any constraints on the wavelength set by any atomic optical transitions. Thus, in principle, the power density in an FEL can be quite high, and the wavelength adjusted to any desired value.

Instead of being limited by the gain medium, the maximum IFEL power density would be set by cooling the dielectric and ferromagnetic materials used in the magnetic pulse sources and accelerator modules of Fig. 5. Storing typical energy densities (in a single pulse) of $100 \mathrm{~J} / \mathrm{kg}$, the "intrinsic" IFEL specific power in the accelerators active media,

$$
\alpha_{\text {IFEL }}(\text { intrinsic }) \approx 0.1 \mathrm{~kJ} / \mathrm{kg} \times \mathrm{F}_{\text {rep }}(\mathrm{Hz}),
$$

depends on the pulse repetition rate $F_{\text {rep }}$. With solid-state switching, the upper limit on $F_{\text {rep }}$ set by cooling is currently expected to be 10 to $20 \mathrm{kHz}$. Thus, intrinsic $a_{\text {IFEL }}>10^{3} \mathrm{~kW}_{\mathrm{e}} / \mathrm{kg}$ are possible. Of course, the overall IFEL system specific power will be much lower due to structure, wigglers, power supplies, and space radiators for cooling. Thus, the maximum system $a_{\text {IFEL might not be much larger than } 1 \mathrm{~kW}} / \mathrm{kg}$. At this specific power, the laser system mass will be dominated by the structure, power supplies, and radiators. 
The transmitter to direct the laser beam out of the FEL to the spacecraft photovoltaic receiver millions of kilometers away must be very large, both to limit diffraction losses (discussed later) and to allow adequate cooling at the high beam power levels envisioned. To achieve diffraction-limited beam quality, the favored approach is to subdivide a large aperture transmitter of overall diameter $D_{t}$ into many smaller mirror segments. Each segment would be a thin, hexagonal wafer supported and adjusted by a set of three small, computer-controlled electromagnetic or piezoelectric actuators. In this way, arbitrarily large arrays of phased optical transmitters could be constructed at a moderate areal mass of about $40 \mathrm{~kg} / \mathrm{m}^{2}$. Balancing beam losses (using optical coatings) with radiative cooling would limit average beam intensity to about $100 \mathrm{~kW} / \mathrm{m}^{2}$. This corresponds to a transmitter specific power of 2.5 $\mathrm{kW}_{\text {beam }} / \mathrm{kg}$, contributing $10 \%$ as much mass as the IFEL at $1 \mathrm{~kW} / \mathrm{kg}$ and $25 \%$ efficiency.

The adaptive optics would control the beam-phase front to within a small fraction of a laser wavelength, correct for thermal and gravitational distortions, and provide a small angular range of electronic beam steering. The beam would most likely be directed to a relay mirror (also adaptive) at a high synchronous lunar orbit and then redirected to track the spacecraft. The spacecraft receiver would best be a large diameter $D_{r}$, parabolic foil collector $\left(\leq 10^{-2} \mathrm{~kg} / \mathrm{m}^{2}\right.$ areal mass, $D_{r} \sim 1000 \mathrm{~m}$ diameter $)$, which concentrates the laser beam onto a smaller $\left(D_{f} \sim 100 \mathrm{~m}\right)$ photovoltaic array of diameter $D_{f}$ at much higher areal mass $\left(\leq 1 \mathrm{~kg} / \mathrm{m}^{2}\right)$. The characteristics of this photovoltaic array are discussed next. Then the allowed laser transmission range versus laser power will be estimated.

\section{PHOTOVOLTAIC RECEIVER CHARACTERISTICS}

Photovoltaic conversion efficiencies with spectrally narrow laser light can be much higher than with solar radiation, much of the latter spectrum falling uselessly outside the semiconductor bandgap. ${ }^{3}$ A promising photovoltaic candidate for a LASERPATH mission to Mars is thin diamond-film semiconductor, now under development at several laboratories. With a 5-eV 
bandgap energy, $E_{b}$, a high conversion efficiency (e.g., 70\%) might be achieved with UV laser wavelengths of 100 to $200 \mathrm{~nm} .{ }^{4}$ Furthermore, the conversion efficiency, should remain high up to higher temperatures, allowing more waste heat radiation off the wafer backsides.

For $100-\mu$-thick thin-film photovoltaic array at $1 \mathrm{~kg} / \mathrm{m}^{2}$ areal mass (including structure) and an equal total foil collector mass, a specific power of $10 \mathrm{~kW} / \mathrm{kg}$ would require an average laser intensity of $30 \mathrm{~kW} / \mathrm{m}^{2}$ on the photovoltaics ( $300 \mathrm{~W} / \mathrm{m}^{2}$ on the foil collector), to produce $20 \mathrm{~kW} / \mathrm{e}^{2}$ of photovoltaic area. The waste heat radiated would be $10 \mathrm{~kW} / \mathrm{th}^{2}$ off the back side, giving an equilibrium photovoltaic temperature of $670 \mathrm{~K}$.

An important consideration for manned missions is reliability, with backups to system failure if possible. With 4-month one-way trip times, failure of the lunar-based reactor or laser may permit time to repair (if the failure occurs midcourse), using the lunar-based infrastructure or even shipping spare parts from Earth. Building in redundancy (an extra reactor and laser, for example) also helps. But ultimately, if all else fails, a LASERPATH system has an emergency backup energy source, albeit with less usable power: the sun. In principle, the large foil collectors envisioned could also deliver solar radiation to the photovoltaics, up to the limit imposed by photovoltaic temperature limits and waste heat radiation. For diamond photocells, the bandgap accepts only a slice of the less intense solar UV spectrum, so the solar conversion efficiency would probably be low, perhaps only 1 to $2 \%$. Nonetheless, since the concentrated solar flux and operating temperature can be higher, the diamond photovoltaic array might still have solar output of electricity comparable to conventional silicon solar cells $\left(\approx 0.2 \mathrm{~kW}_{\mathrm{e}} / \mathrm{m}^{2}\right)$. With emergency solar power, a LASERPATH vehicle could limp home, provided it was not nearly out of propellant when the laser failure occurred. The astronauts may get a higher dose of radiation with a longer solar-powered trip home, but they would still survive.

\section{RANGE OF LASER-POWER TRANSMISSION}

Now that we have determined laser intensities at the lunar-based transmitter $\left(100 \mathrm{~kW} / \mathrm{m}^{2}\right)$, and on the photovoltaic array $\left(30 \mathrm{~kW} / \mathrm{m}^{2}\right.$ within $D_{f}$, the collector focus), we can determine a relationship between average laser 
power $P_{L}$ and range $R$ between the transmitter and the foil receiver (collector), provided we specify the ratio of foil receiver diameter to photovoltaic (focus) diameter, $D_{r} / D_{f}$ :

$$
\begin{aligned}
& D_{r}=\left(\frac{D_{r}}{D_{f}}\right) \quad D_{f}=\left(\frac{D_{r}}{D_{f}}\right)\left[\left(\frac{4}{\pi}\right)\left(\frac{0.9 P_{L}(W)}{3 \times 10^{4}\left(W / \mathrm{m}^{2}\right)}\right)\right]^{1 / 2} \\
& D_{t}=\left[\left(\frac{4}{\pi}\right)\left(\frac{P_{L}(W)}{10^{5}\left(W / \mathrm{m}^{2}\right)}\right)\right]^{1 / 2}
\end{aligned}
$$

Now, diffraction relates the product $D_{r} D_{t}$ to the range $R$ and the laser wavelength $\lambda$ according to:

$$
D_{r} D_{t}=2.44 R \lambda=220 \quad P_{L}(M W) \text {, }
$$

where we have used Eqs. 1 and 2. The results are plotted in Fig. 6 for various wavelengths $\lambda$. Figure 6 shows that for the short UV wavelengths we assumed, a LASERPATH mission to Mars can be achieved with 200 MW of laser power. Longer wavelength lasers require either more power or several laser stations enroute, to decrease the range requirement. Eventually, for regular manned shuttles supporting a permanent base, it would be advantageous to install at least one additional reactor and UV laser on the Martian moon Phobos.

From the mission requirements plotted in Fig. 3, we see that a 0.7 -year roundtrip travel time (25-rem dose) requires $129 \mathrm{MW}_{\mathrm{e}}$ for a $10 \mathrm{~kW} / \mathrm{kg}$ specific power. With a $90 \%$ foil collection efficiency and a $70 \%$ conversion efficiency, the required laser beam power is $129 /[(0.9)(0.7)] \approx 200 \mathrm{MW}$. Thus, there is a good match between the mission requirements and the LASERPATH power system performance.

\section{LUNAR REACTOR MASS}

Finally, we can address the performance requirements for lunar-based reactors (or other power sources) to power the LASERPATH mission to Mars. Such lunar-based power sources could in principle be fission or fusion reactors, or even large solar power stations, as envisioned in Glaser's solar 
power satellite proposal ${ }^{5}$ or Waldron and Criswell's lunar solar power proposal. ${ }^{6}$ In any case, we inquire whether or not the propellant and vehicle mass savings made possible by laser-driven photovoltaics could offset the greater reactor or power source mass incurred by the inefficiency of laser conversion in the LASERPATH scheme. Taking our IFEL laser example with a conversion efficiency of $25 \%$, the 200-MW laser power output demands an $800-M W_{e}$ lunar-based power source, ten times the $80 \mathrm{MW}$ required for an on-board power source with the $0.33-\mathrm{kW} / \mathrm{kg}$ specific power necessary to meet the same 0.7 -year roundtrip mission (see Fig. 3). If we assume the vehicles are reusable (but keep a spare vehicle), we can compare the sum of the vehicles' power/propulsion system mass and the total propellant consumed for say, 10 roundtrips (20 years, given the 2-year Earth-Mars Synodic period), with the corresponding sum in the LASERPATH case plus the added mass of the laser $\left(M_{\text {laser }}=800 \mathrm{MW}_{\mathrm{e}} / 0.9 \mathrm{~kW} / \mathrm{kg}\right.$ metric tons, including the transmitter optics, laser power conditioning, cooling, and supports) and the added mass of the reactor $\left(M_{\text {reactor }}=800 \mathrm{MW}_{\mathrm{e}} / a_{r}\right)$. Such comparisons are presented in Table 1 , for two on-board power sources characterized by $a_{r}=0.33 \mathrm{~kW} / \mathrm{kg}$ (the minimum required for the mission--case 1 ), and $a_{r}=1 \mathrm{~kW} e / \mathrm{kg}$ (case 2), to represent the aspiration of more advanced fusion-powered vehicles, to be compared with two LASERPATH examples (cases 3 and 4) characterized by lunar-reactor specific powers of 0.33 and $0.067 \mathrm{~kW}_{\mathrm{e}} / \mathrm{kg}$, respectively.

As the specific detail of optimized lunar reactor designs is beyond the scope of this work, I characterize such reactors by specifying only their specific power. The lunar reactor case 3 with $0.33 \mathrm{~kW} / \mathrm{kg}$ is chosen to compare with case 1, having the same specific power for an on-board reactor that can barely meet the mission requirement. The lunar reactor case 4 with $0.067 \mathrm{~kW}_{\mathrm{e}} / \mathrm{kg}$ is chosen to 117 ustrate what happens with a specific power no better than SP-100 nuclear units, which cannot meet the Mars mission as onboard reactors (at least, with $<25-$ rem roundtrip dose constraints).

\section{LUNAR MASS UTILIZATION}

Normally, we compare total mass between competing space power systems meeting the same mission, since transportation costs to Low Earth Orbit (LEO) could likely dominate over terrestrial material and fabrication costs for 
space systems $>10^{3}$ tons. When that is the case, the unit costs of very different materials and fabrications tend to be closer to the same transportation costs per unit mass. This would be even more likely for lunar space systems, if transport from the Earth to the Moon were required.

The National Aeronautics and Space Administration (NASA) office of exploration is sponsoring studies on possible uses of lunar materials for space development, and ways to manufacture various commodities and structures on the moon. For example, heavy radiation shielding might be made of lunar concrete; iron-nickel micrometeorite particles collected from lunar soil might provide steel structures; and traces of low-atomic-number solar-wind gases trapped in the finer lunar dust can be outgassed by heating $\mathrm{CH}_{2}, \mathrm{H}_{2} \mathrm{O}, \mathrm{He}, \mathrm{CO}_{2}$, etc). Without a detailed design, we cannot determine what fraction $f_{m}$ of a given lunar system, such as a reactor, could be made of indigenous lunar materials. However, if a substantial fraction of reactor systems (which might be dominated by structures, shielding, transformer iron in power supplies, etc.) could be made of lunar materials, and furthermore, if such a fraction differed for different types of reactors (as is likely), then the important comparison between competing propulsion systems would be the total mass minus any lunar-origin mass, i.e., the mass portion that must be transported from Earth. This assumes that the unit cost of Earth-origin mass much exceeds the unit cost of lunar-origin mass, which would be the case if the total lunar mass of each type produced were a large multiple of the initial investment of lunar mining and manufacturing equipment mass. If the lunar production equipment mass were not negligible, it could be included as an effectively smaller lunar mass utilization factor $f_{m}$.

I will not attempt to fully justify the $f_{m}$ values assumed in Table 1, which are picked primarily to illustrate how the impact of large $f_{m}$ fractions might change the comparative system economics of the various cases. I inserted some logic to the $f_{m}$ assumptions: for the $f_{m}$ values pertaining to power generation and conversion (reactors and lasers), I supposed that $f_{m}$ can in general increase with decreasing specific power, on the argument that, the higher the specific power, the narrower the choice of materials that can reach the higher performance levels, and the more likely such specialty materials must be transported from Earth. Thus, I chose $f_{m}=0.02$ for $\alpha=10,0.18$ for $\alpha=1,0.45$ for $\alpha=0.33$, and 0.95 for $\alpha=0.067$, for either reactors or lasers, which reflects this tendency, although the actual values are 
arbitrary. For magnetic fusion, of which I am most familiar, an $f_{m}=0.95$ might be feasible. At $800 \mathrm{MW}_{e}$ and $a_{r}=0.067$, a 12,000 -ton $\mathrm{D}-{ }^{3} \mathrm{He}$ tokamak ${ }^{7}$ might consist of 4000 tons of superconducting magnets (consisting of 3400 tons of iron-nickel steel structure, 300 tons of aluminum stabilizer, and 300 tons of superconducting wire), 3000 tons of steel neutron shielding, 2000 tons of blankets (which could be a simple, helium-cooled, ferritic steel structure), 2700 tons of heat-injection space radiators (mainly low-pressure steel tubing), and 300 tons of solid-state microwave rectenna converters. If meteorite-derived steel can be used, there would be essentially only 600 tons of superconductor and rectenna converters to import from Earth.

As for the vehicle propellant, defining the lunar-derived propellant fraction as $f_{m p}$, I assumed $f_{m p}=0$ and 0.7 , to illustrate the impact of using imported propellant $\left(f_{m p}=0\right)$, such as argon or sodium, or using lunar-derived propellant $\left(f_{m p}=0.7\right)$, such as hydrogen. Most electric-powered plasma thrusters-would run on either heavy noble gases, alkali metals, mercury, or cesium, none of which are likely to be lunar indigenous, due to their intrinsic volatility. Although hydrogen is difficult to use in electric thrusters and difficult to store for long periods, these problems might be overcome in the future. The hydrogen exists only in trace amounts in lunar soil, so $f_{m p}$ should be $30 \%$ less than unity to account for the hydrogen extraction, liquefaction, and storage equipment mass.

CONCLUSIONS

From the results in Table 1 we can draw some conclusions (some more qualitative than quantitative, until more analysis is done).

(1) The rationale for LASERPATH hinges mainly on how high a specific power fission, fusion, or solar power systems can be developed for powering manned vehicles: if, for example, sufficiently advanced fusion reactors could achieve $a_{r}=1 \mathrm{~kW} / \mathrm{kg}$, then it would be best to pursue the conventional approach, with the reactor carried on-board. If, however, $a_{r} \ll 0.33 \mathrm{~kW} / \mathrm{kg}$, then a mission with less than 0.7 -year travel time and 25-rem doses cannot be achieved at all with on-board reactors. In this case the LASERPATH approach might meet the mission requirement with lower 
specific mass reactors, and with comparable total mass investment as if $\alpha_{r}=0.33 \mathrm{~kW}_{\mathrm{e}} / \mathrm{kg}$ reactors were available.

(2) The viability of LASERPATH depends on the development of advanced photovoltaics, adaptive transmitter optics, and efficient free electron lasers, all of which appear to be promising but remain to be demonstrated at the performance levels needed. NASA should encourage and participate in such developments, as a hedge against the uncertainty of reactors reaching the high specific powers required for on-board power systems.

(3) The actual commitment of mass transport from Earth to establish lunar power reactors and lasers might be heavily influenced by the availability and suitability of lunar materials in their construction. NASA should sponsor a study, in conjunction with the ongoing lunar resource studies, to explore the degrees to which different lunar power sources--fission, fusion, and solar--can utilize lunar materials, and in doing so, encourage innovative thinking from reactor designers to exploit lunar materials more fully, i.e., reoptimize the reactor designs for the lunarbased development.

(4) As the duty factor powering Mars missions every 2 years is only 35\%, an investment in a lunar LASERPATH system can be further leveraged by using the laser or the reactor electricity for various space enterprises, in between Mars shots. 


\section{REFERENCES}

(1) R.D. Arno, J.S. MacKay, and K. Nishioka, "Applications Analysis of High Energy Lasers," NASA AMES report NASA TM X-62,142 (March 1972).

(2) W.J. Schafer Associates, Inc., "A Study to Survey NASA Laser Applications," in Space Laser Transmission Studies, by M.D. Williams and E.J. Conway, Eds., NASA Conference Publication 2214 (1982).

(3) G.H. Walker and J.H. Heinbockel, "Photovoltaic Conversions of Laser Power to Electrical Power," NASA Langley report NASA TM 89041 (Sept. 1988).

(4) B.G. Logan, "Initiative for the 21st Century: Advanced Space Power and Propulsion Based on Lasers," Seminar given at NASA Lewis Research Center, April 26, 1988. Lawrence Livermore National Laboratory, Report UCRL98520 (preprint).

(5) P. Glaser, "Solar Power from Satellites," Physics Today, (Feb. 1977) p. 30 .

(6) R.D. Waldron and D.R. Criswell, "Concept of the Lunar Power System," Space Solar Power Review 5 , 53 (1985).

(7) G.L. Kulcinski, G.A. Emmert, J.P. Blanchard, L. El-Guebaly, H.Y. Khater, J.F. Santarius, M.E. Sawan, I.N. Sviatoslavsky, L.J. Wittenberg, and R.J. Witt, "Apollo--An Advanced Fuel Fusion Power Reactor for the 21st Century," University of Wisconsin Fusion Technology Institute, Report UWFDM-780 (Oct. 1988). 
Table 1. Case Comparisons of Propulsion System Mass: On-Board Reactors versus Lunar-Based Reactors + Laser Transmission.

\begin{tabular}{|c|c|c|c|c|}
\hline & $\begin{array}{l}\text { Case } 1 \\
\text { On-Board } \\
\text { Reactor }\end{array}$ & $\begin{array}{l}\text { Case } 2 \\
\text { On-Board } \\
\text { Reactor }\end{array}$ & $\begin{array}{l}\text { Case } 3 \\
\text { Lunar-Based } \\
\text { Reactor }\end{array}$ & $\begin{array}{l}\text { Case } 4 \\
\text { Lunar-Based } \\
\text { Reactor }\end{array}$ \\
\hline Parameter $\left(\mathrm{kW}_{\mathrm{e}} / \mathrm{kg}\right)$ & 0.33 & 1 & 0.33 & 0.067 \\
\hline Manned Mars Vehicle & 80 & 115 & $129^{a}$ & 129 \\
\hline Specific Power $\mathrm{kW}_{\mathrm{e}} / \mathrm{kg}$ & 0.33 & 1 & 10 & 10 \\
\hline $\begin{array}{l}\text { Two-Vehicle Power } \\
\text { System Mass (MT) }\end{array}$ & $480(264)^{b}$ & $115(94)$ & $26(25)$ & $26(25)$ \\
\hline $\begin{array}{l}\text { Propellant (MT) for } \\
10 \text { roundtrips }\end{array}$ & $6300[1890]^{C}$ & $908[272]$ & $160[48]$ & $160[48]$ \\
\hline $\begin{array}{l}\text { Lunar-Based Reactor } \\
\text { Mass (MT) }\end{array}$ & NA & NA & $2400(1320)$ & $12,000(600)$ \\
\hline $\begin{array}{l}\text { Lunar-Based Laser }+ \\
\text { Transmitter Mass (MT) }\end{array}$ & NA & NA & $800(722)$ & $880(722)$ \\
\hline \multicolumn{5}{|l|}{ Total Power/Propulsion } \\
\hline System $^{\mathrm{d}}$ Mass (MT) & 6780 & 1023 & 3466 & 13,066 \\
\hline $\begin{array}{l}\text { Total Power/Propulsion } \\
\text { System Mass (MT), Non- } \\
\text { Lunar Origin, if } f_{m p}=0\end{array}$ & $(6564)$ & $(1002)$ & $(2227)$ & (1507) \\
\hline $\begin{array}{l}\text { Total Power/Propulsion } \\
\text { System Mass (MT), Non- } \\
\text { Lunar Origin, if } f_{m p}=0.7\end{array}$ & [2154] & {$[366]$} & [2115] & [1395] \\
\hline
\end{tabular}

Assumptions: 133-ton payload, 250-day roundtrip travel time, (25-rem roundtrip dose), 2 vehicles (one for standby), specific power of lunar-based laser + optics system $=0.9 \mathrm{~kW} / \mathrm{kg}$. Lunar-mass-utilization factors $f_{m}: 0.02$ for $\alpha=10,0.18$ for $\alpha=1,0.45$ for $\alpha=0.33,0.95$ for $\alpha=0.067 \%$ propel lant $f_{m p}=0$ or 0.7 (as indicated).

${ }^{a_{F o i l}}$ concentrators + photovoltaic array for vehicle power (case 3 and 4 ).

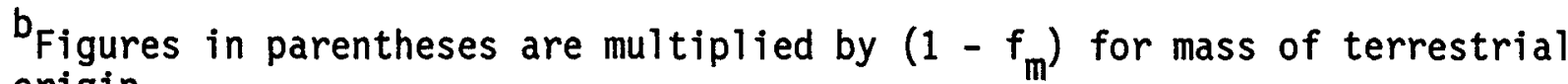
origin.

CFigures in bracket adjusted by $\left(1-f_{m p}\right)=0.3$ factor for propellant.

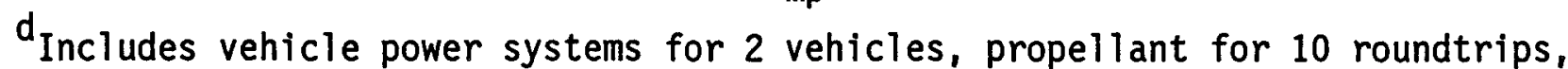
and lunar-based reactors and lasers, where appropriate. 


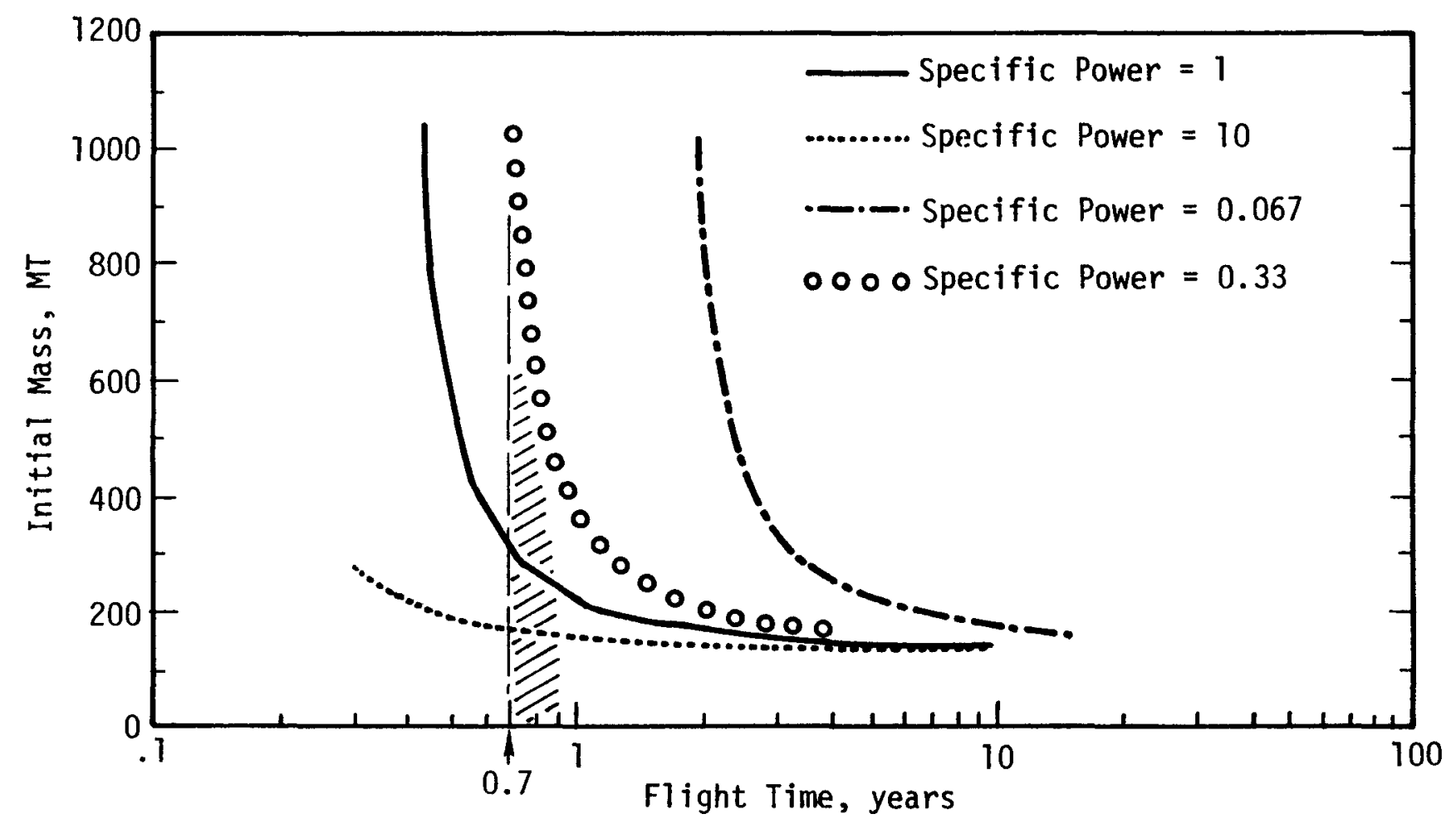

FIGURE 1 Initial vehicle mass variations with flight duration for manned missions to Mars.

[From N. Schultz, "Space Fusion Energy for a High Energy Class of Space Missions." NASA HQ report, to be published] 


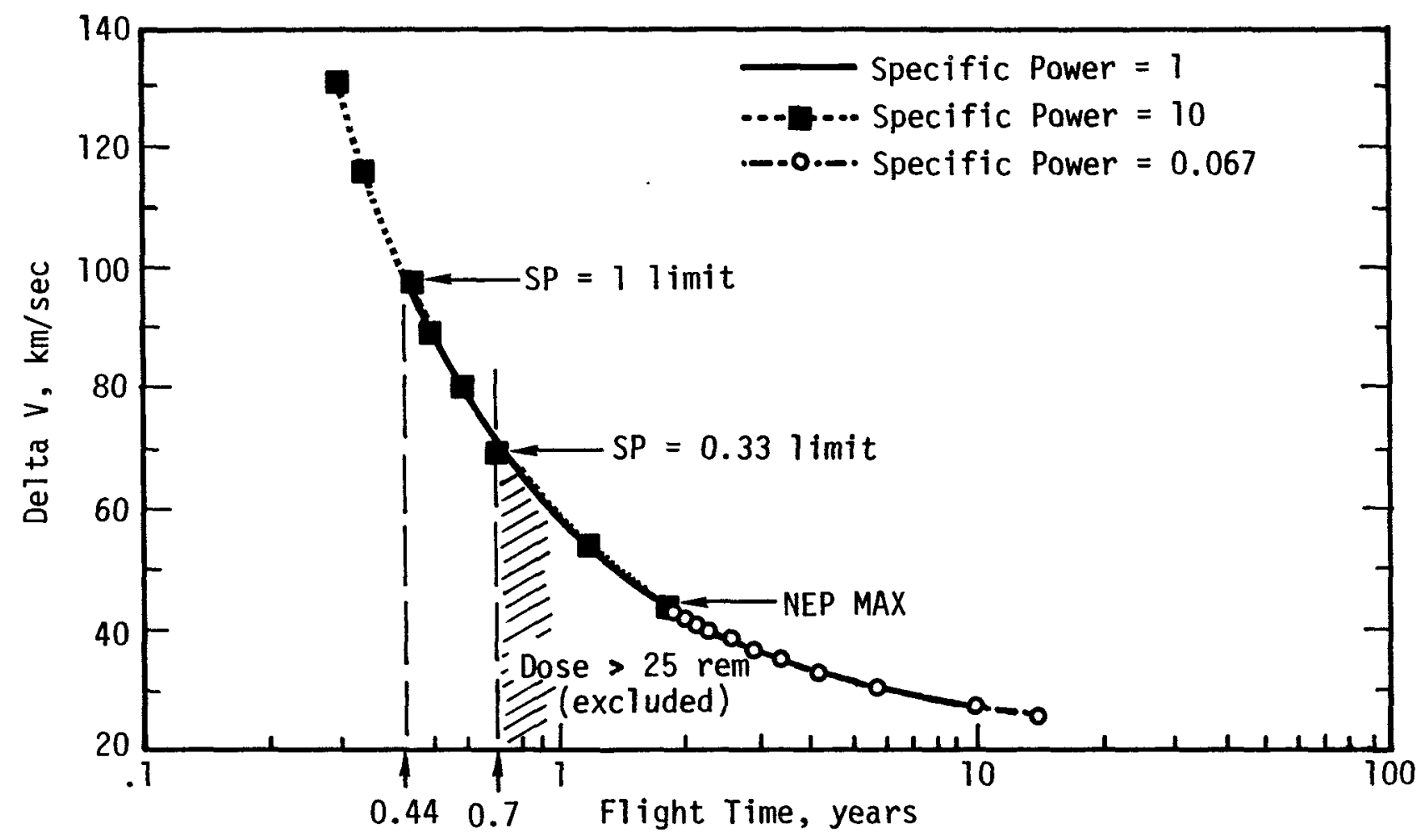

FIGURE 2 Vehicle velocity variations with flight duration for manned missions to Mars. [From N. Schultz, "Space Fusion Energy for a High Energy Class of Space Missions," NASA HQ report, to be published.] 


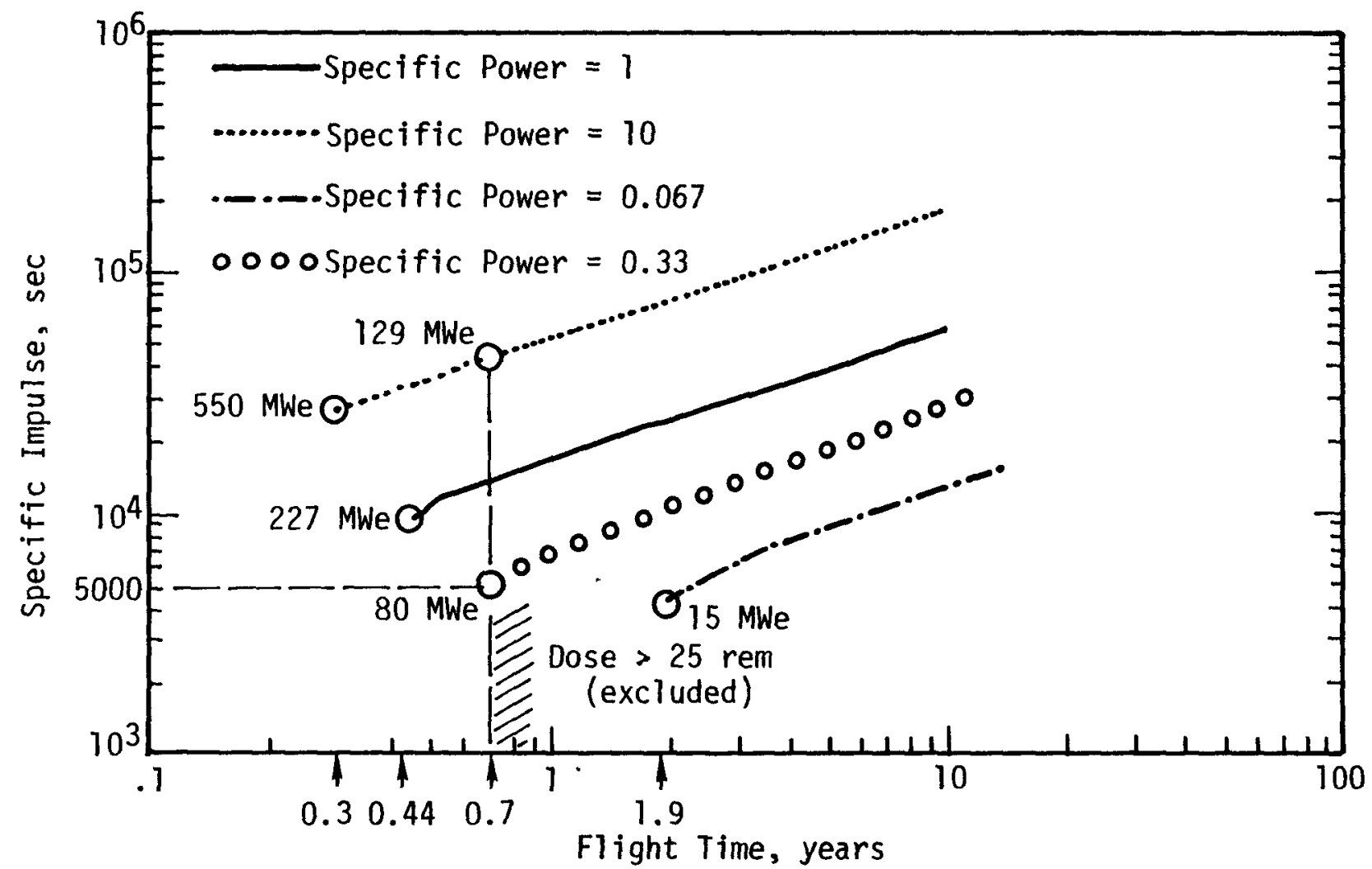

FIGURE 3 Specific impulse variations with flight duration for manned missions to Mars.

[From N. Schultz, "Space Fusion Energy for a High Energy Class of Space Missions," NASA HQ report, to be published.] 


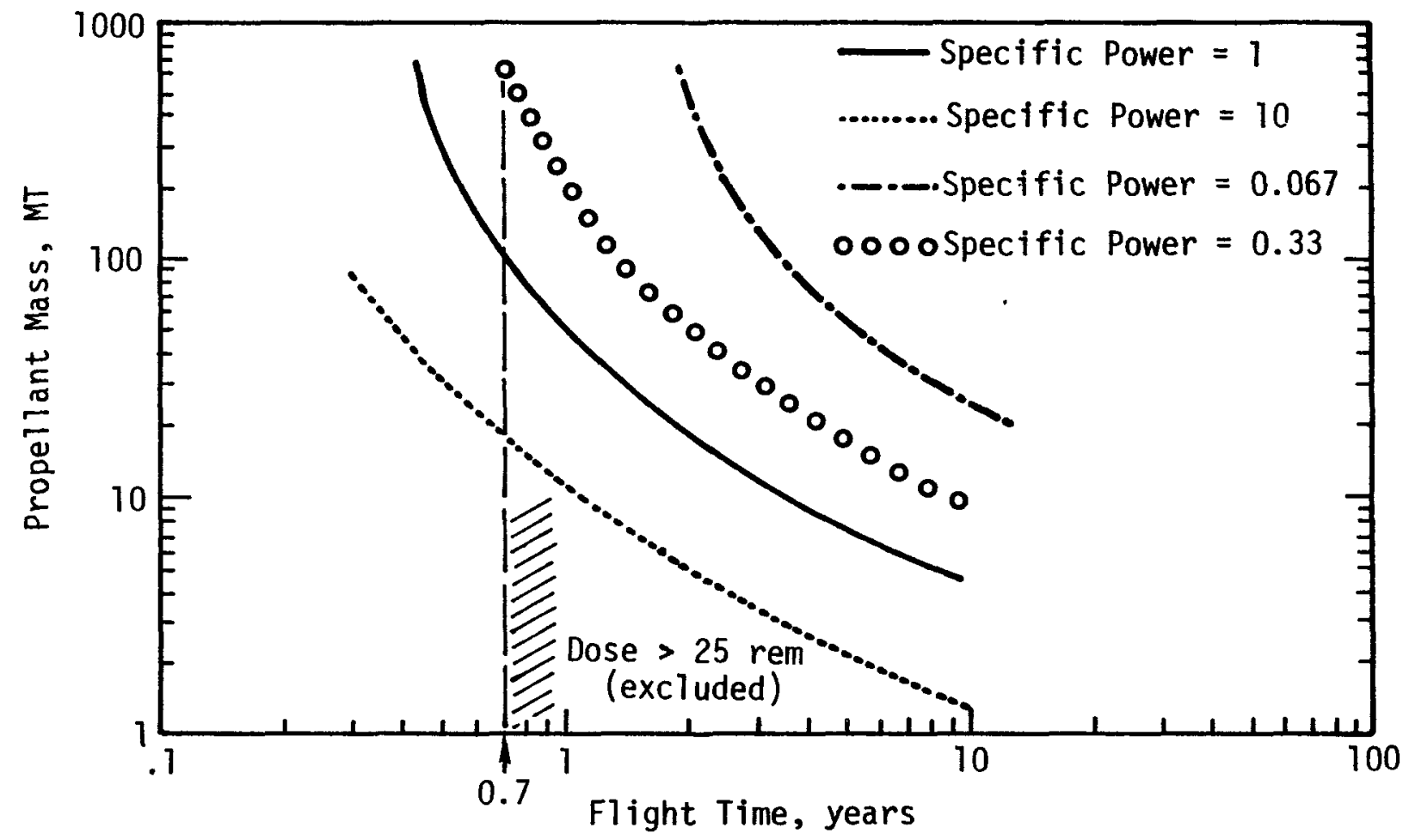

FIGURE 4 Propellant mass variations with fliaht duration for manned missions to Mars. [From N. Schultz, "Space Fusion Energy for a High Energy Class of Space Missions," NASA HQ report, to be published.] 


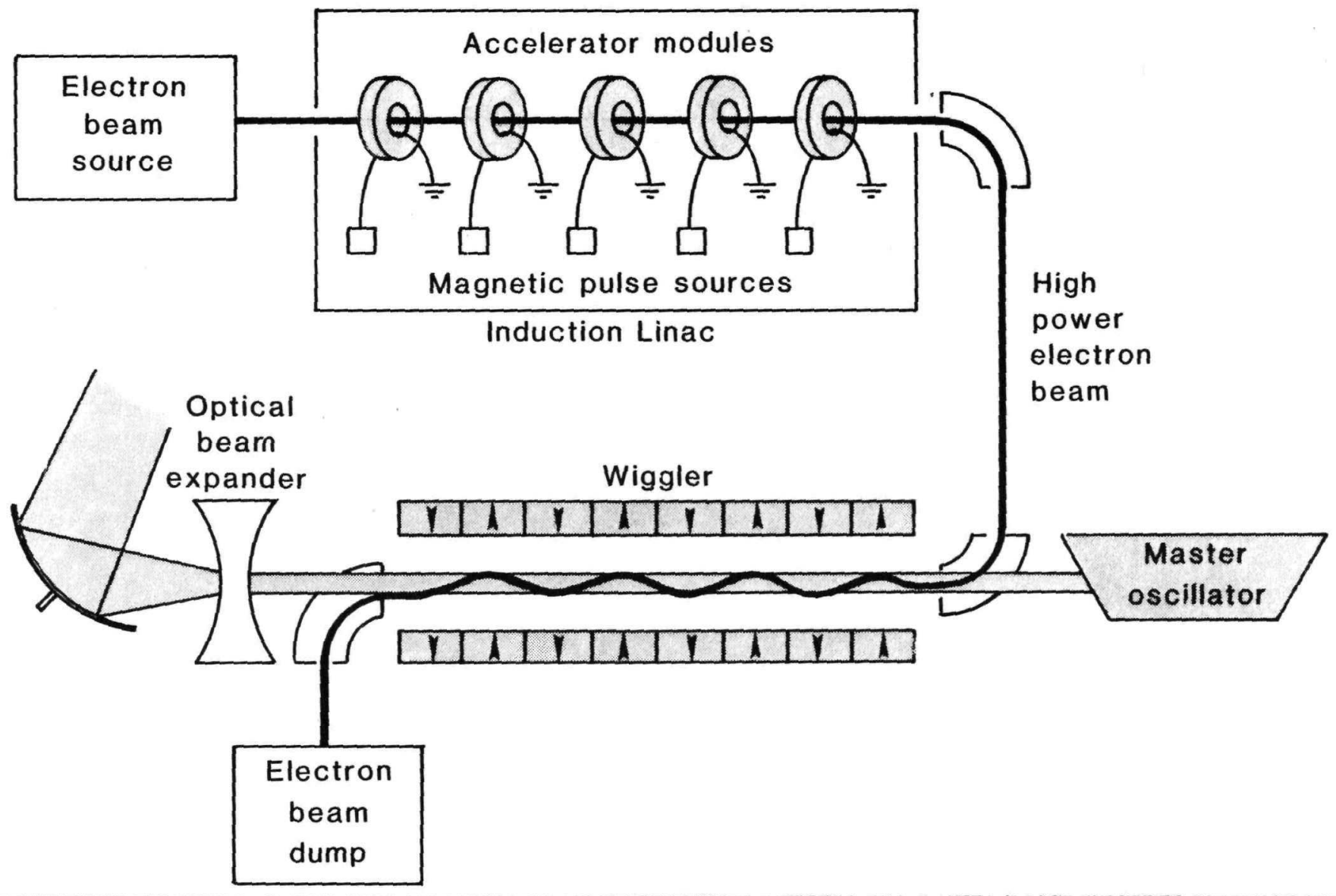

FIGURE 5 Schematic representation of the FEL system, including the Linac, a wiggler, its driving source, and the output transmission system. 


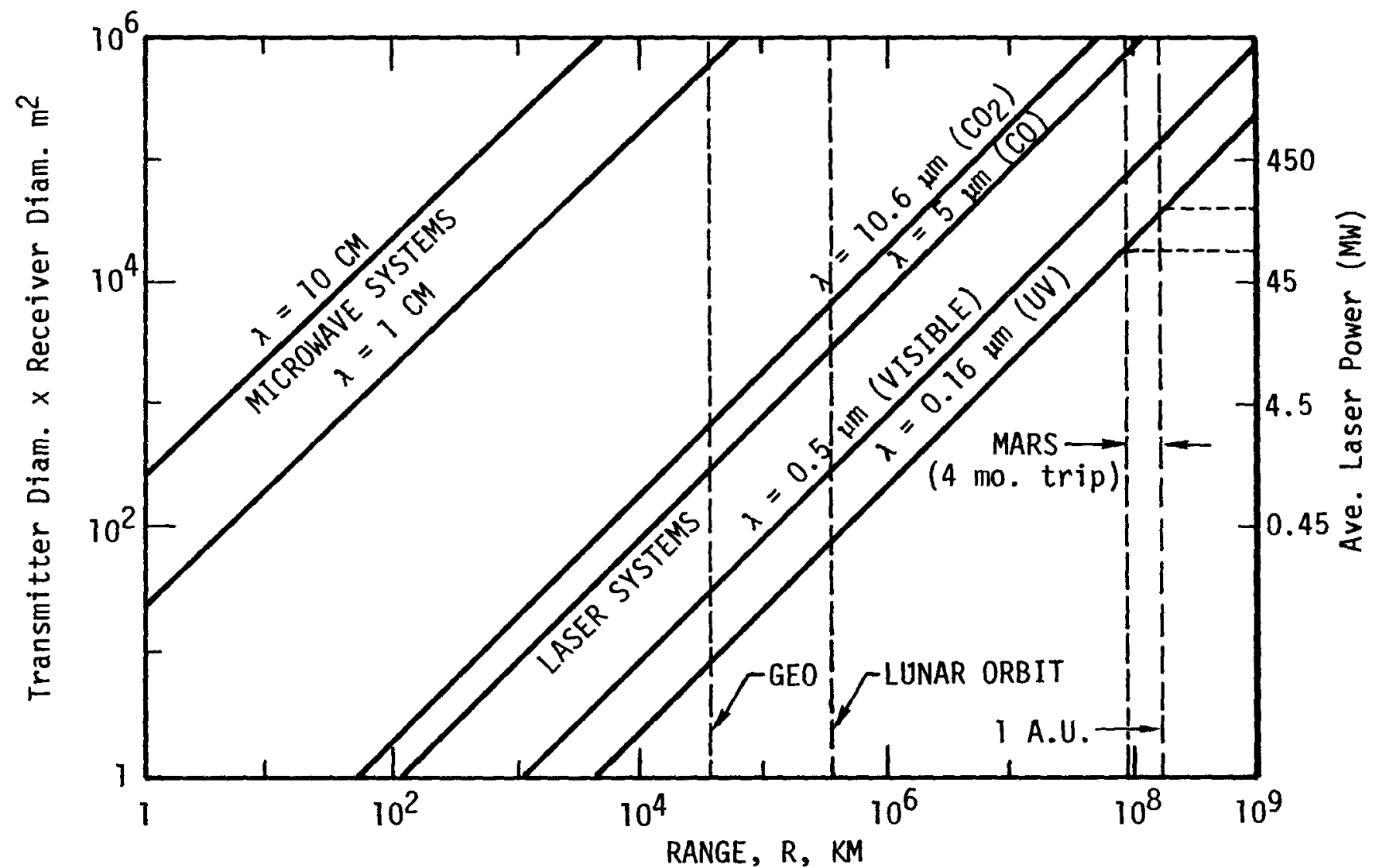

FIGURE 6 Product of transmitter and receiver apertures (left scale) and average laser power (right scale) as a function of range between transmitter and receiver. Transmitter laser intensity $=100 \mathrm{~kW} / \mathrm{m}^{2}$; receiver laser intensity $=300 \mathrm{~W} / \mathrm{m}^{2}$. 
